\title{
Biomimetic Coatings on Fiber Laser Modified Ti-6Al-4V Surfaces
}

\author{
T.F. Hong ${ }^{* 1,2}$, L.M. Fu ${ }^{1,3}$, B.S. Wu ${ }^{1,2}$, K.Y. Lin ${ }^{2}$, H.K. Lin ${ }^{1}$, T.Y. Kuo ${ }^{4}$ \\ ${ }^{1}$ Graduate Institute of Materials Engineering, National Pingtung University of Science and Technology, Pingtung, TAIWAN. \\ ${ }^{2}$ Department of Vehicle Engineering, National Pingtung University of Science and Technology, Pingtung, TAIWAN. \\ ${ }^{3}$ Department of Biomechatronics Engineering, National Pingtung University of Science and Technology, Pingtung, TAIWAN. \\ ${ }^{4}$ Department of Mechanical Engineering, Southern Taiwan University of Science and Technology, Tainan, TAIWAN. \\ *tfhong@mail.npust.edu.tw
}

This study compares and analyses the properties of Ti-6Al-4V surfaces affected by a fiber laser with two different output power levels $(6.7$ and $13.5 \mathrm{~W})$. The fiber laser modified Ti-6Al-4V samples were immersed in a modified artificial simulated body fluid (m-SBF) solution and a supersaturated $1.5 \mathrm{~m}-\mathrm{SBF}$ for a period of time to evaluate their bioactivity and biomimetic bone-like apatite coating performances, respectively. The results revealed that the surface morphology, hardness and hydrophilicity of Ti-6Al-4V were improved after laser modification, and a $13.5 \mathrm{~W}$-treated sample had a relatively higher hardness value and more outstanding hydrophilicity compared with its $6.7 \mathrm{~W}$-treated counterpart. Furthermore, the laser treated samples were found to have a more favorable $\mathrm{Ca}$ and $\mathrm{P}$ inducibility in the $\mathrm{m}-\mathrm{SBF}$, where crystallized hydroxyapatite-rich bone-like apatite was found on their surfaces after immersing them in the m-SBF solution for a period of time. This bone-like apatite layer can be rapidly grown on the specimens when immersed in the $1.5 \mathrm{~m}-\mathrm{SBF}$ solution for only 3 days, indicating its favorable biomimetic coating efficiency.

DOI: $10.2961 / \mathrm{jlmn} .2016 .02 .0002$

Keywords: Ti-6Al-4V; fiber laser; surface modification; SBF; biomimetic coating

\section{Introduction}

Titanium (Ti) and its alloys are ideally suitable for medical implants due to their favorable mechanical and biological compatibility along with stability. However, they do not easily form chemical bonds with the host tissue due to their bioinertness. Therefore, creating a bioactive layer on their surfaces is normally considered for a permanent implant application. Several surface modification techniques, such as plasma spraying, sol-gel, electrical chemical, biomimetic, and laser methods [1-6], were developed for preparing such bioactive surfaces. Owing to high coherence and directionality, a laser beam can perform a broad range of treatments, such as remelting [7], alloying [8] and cladding [9], to change the surface morphology, chemical and physical properties, and also enhance wear and corrosion resistance of the target material. Therefore, considerable concern has arisen over laser surface modification of titanium and its alloys in recent years.

Laser surface modification techniques have been applied on medical Ti-based implant applications recently [10-17], and a lot of research has been focused on the study of surface oxides obtained via a laser process [13-16] since they can affect the biological and mechanical compatibility of these Ti-based materials. Our previous study revealed that due to the rougher and more open titanium oxide enriched surfaces, Nd-YAG laser treated Ti-6Al-4V samples were found to have a more favorable $\mathrm{Ca}$ and $\mathrm{P}$ inducibility to form bone-like apatite structures than their furnace annealed counterparts in the m-SBF [17], which indicated a more outstanding bioactivity.

In this study, a fiber laser technique was utilized to modify Ti-6Al-4V substrate surfaces. The influence of laser treatments on the morphology, chemical composition, crystal structure, hardness and wettability of the Ti-6Al-4V surfaces was investigated further. The laser modified specimens were also immersed in $\mathrm{m}-\mathrm{SBF}$ and $1.5 \mathrm{~m}-\mathrm{SBF}$ for different periods of time to evaluate their bioactivity and biomimetic bone-like apatite coating performances, respectively.

\section{Experimental procedures}

\subsection{Fiber laser surface treatments}

A Ti-6Al-4V thin plate was cut into a piece with dimensions of $10 \times 10 \times 1 \mathrm{~mm}^{3}$. The samples were ground with up to 600 grades of $\mathrm{SiC}$ paper and then, ultrasonically cleaned with acetone and deionized water for 20 minutes, respectively. These raw samples underwent fiber laser irradiation under atmospheric conditions with the following modes of operation: pulsed wavelength of 1064 $\mathrm{nm}$, repetition rate of $25 \mathrm{kHz}$, spot diameter of $40 \mu \mathrm{m}$, scanning speed of $100 \mathrm{~mm} / \mathrm{s}$, scan pitch of $2 \mu \mathrm{m}$, pulse width of $5 \mu \mathrm{s}$ and an output set at 6.7 and $13.5 \mathrm{~W}$, respectively. These laser treated samples were then ultrasonically cleaned again with acetone and deionized water for 20 minutes, respectively. All the raw and laser treated samples were coded and summarized as seen in Table 1 for convenient comparisons.

Table 1 Code of raw and laser treated samples

\begin{tabular}{cc}
\hline Code & Sample \\
\hline Ti-6Al-4V & Raw Ti-6Al-4V \\
L-6.7W & Laser treated with $6.7 \mathrm{~W}$ power \\
L-13.5W & Laser treated with $13.5 \mathrm{~W}$ power \\
\hline
\end{tabular}




\subsection{Bioactivity evaluation and biomimetic coating}

The fiber laser modified Ti-6Al-4V samples were immersed in a modified artificial simulated body fluid (m-SBF) solution or a supersaturated $1.5 \mathrm{~m}-\mathrm{SBF}$ at $37^{\circ} \mathrm{C}$ in an atmosphere incubator for different periods of time. The samples were immersed in the m-SBF for up to 21 days to evaluate their in vitro bioactivity [18] and in the $1.5 \mathrm{~m}-\mathrm{SBF}$ for up to 7 days to compare their biomimetic bone-like apatite coating performances. During the immersion in the incubator, the solutions were replaced every two days in order to prevent ion concentration change. All the immersed samples were rinsed with deionized water and then dried before further characterization was taken. The ion concentrations of $\mathrm{m}-\mathrm{SBF}$ and $1.5 \mathrm{~m}-\mathrm{SBF}$ are given in Table 2 [19].

Table 2 The ion concentration of used $\mathrm{m}-\mathrm{SBF}$ and $1.5 \mathrm{~m}-\mathrm{SBF}[18]$

\begin{tabular}{cccccccccc}
\hline \multirow{2}{*}{ Solution } & \multicolumn{7}{c}{ Ion Concentrations ( mM) } \\
\cline { 2 - 9 } & $\mathrm{Na}^{+}$ & $\mathrm{K}^{+}$ & $\mathrm{Mg}^{2+}$ & $\mathrm{Ca}^{2+}$ & $\mathrm{Cl}^{-}$ & $\mathrm{HCO}_{3}{ }^{-} \mathrm{HPO}_{4}{ }^{2-}$ & $\mathrm{SO}_{4}{ }^{2-}$ \\
\hline m-SBF & 142.0 & 5.0 & 1.5 & 2.5 & 103.5 & 10.5 & 1.0 & 0.5 \\
\hline $1.5 \mathrm{~m}-\mathrm{SBF}$ & 213.0 & 7.5 & 2.3 & 3.8 & 154.5 & 15.0 & 1.5 & 0.8 \\
\hline
\end{tabular}

\subsection{Equipment}

A surface morphological evolution of these specimens was observed using a field emission scanning electron microscope (FE-SEM, JSM-7600, JEOL). The chemical compositional analysis of these samples was measured using an energy-dispersive X-ray spectrometer (EDS, $\mathrm{X}-\mathrm{MAX}^{\mathrm{N}}$ 80TLE, Oxford). The crystalline structures of the samples were investigated using an X-ray diffractometer (XRD, D8 advance, Bruker). The surface hardness of each sample was acquired using a micro-Vickers hardness testing machine (KK810-969K, Mitutoyo). Finally, the wettability of the samples was measured with m-SBF control liquid using a contact angle analyzer (FTA1000, First Ten Angstroms).

\section{Results and discussion}

\subsection{Surface morphology and chemical composition}

Figure 1 reveals the SEM surface morphology and EDS chemical composition of the raw and laser treated Ti-6Al-4V samples. It is clear that the flat surfaces of raw Ti-6Al-4V became fine, coral-like, rougher structures through a high temperature remelting and rapid cooling laser irradiation process, and also possibly accompanied by laser induced material ejection, evaporation or laser induced chemical oxidation in air in the current study. Furthermore, the laser treated samples had overall lower $\mathrm{Ti}, \mathrm{Al}$ and $\mathrm{V}$, but higher oxygen content than raw Ti-6Al-4V, which indicated oxygen-rich top layers were created on Ti-6Al-4V substrates after laser irradiation under atmosphere conditions. Since the L-13.5W sample was irradiated with higher laser power, it was found that it had a relatively higher oxygen content than its L-6.7W counterpart.

\subsection{Crystalline structures}

The XRD spectra of the raw and laser treated Ti-6Al-4V samples are shown in Fig. 2. In addition to Ti peaks from the raw Ti-6Al-4V sample, the presence of rutile, anatase and $\mathrm{Al}_{2} \mathrm{O}_{3}$ peaks was also observed in the laser-treated counterparts. This indicates that the oxygen dissolved into the structure found in Fig. 1 had already formed crystallized rutile, anatase and $\mathrm{Al}_{2} \mathrm{O}_{3}$ with $\mathrm{Ti}$ and $\mathrm{Al}$, respectively, since $\mathrm{Ti}$ and $\mathrm{Al}$ have a higher oxygen affinity compared with $\mathrm{V}$ at a raised temperature. The L-13.5W sample had a relatively higher rutile, anatase and $\mathrm{Al}_{2} \mathrm{O}_{3}$ spectra compared with its $\mathrm{L}-6.7 \mathrm{~W}$ counterpart due to a richer oxygen content and being processed with a higher laser power. Rutile, anatase and $\mathrm{Al}_{2} \mathrm{O}_{3}$ are renowned biocompatible materials.

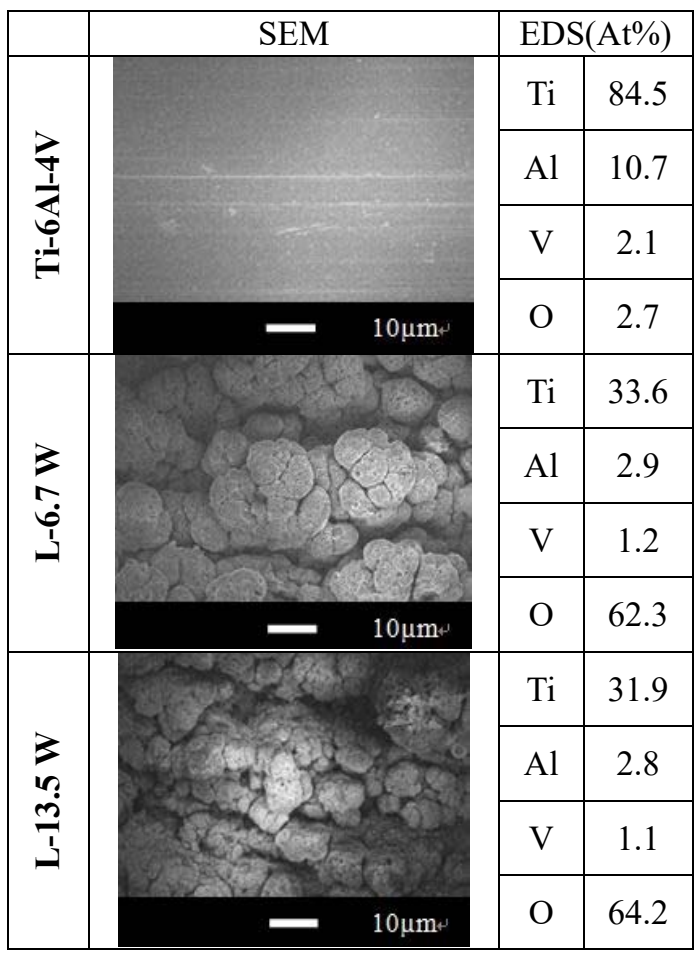

Fig. 1 The SEM image and EDS chemical composition of raw and laser-treated Ti-6Al-4V samples

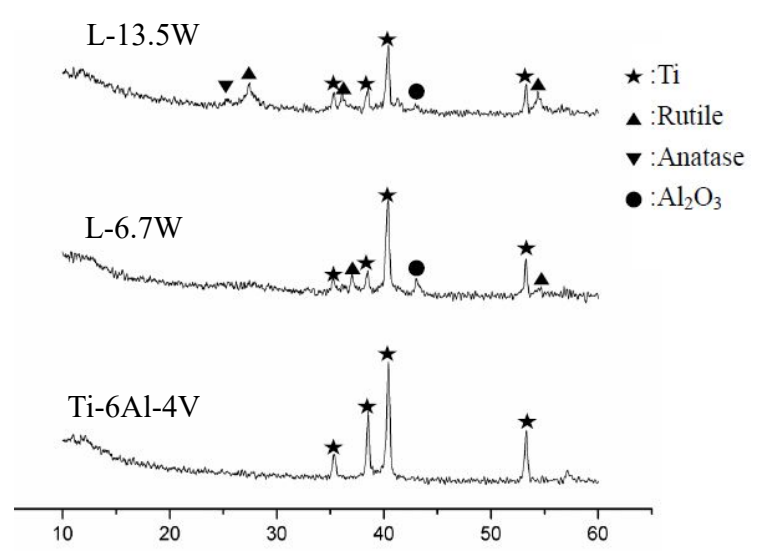

Fig. 2 XRD spectra of raw and laser-treated Ti-6Al-4V samples 


\subsection{Microhardness}

Figure 3 reveals the surfaces' micro-Vickers hardness of raw and laser treated Ti-6Al-4V samples, where the two laser-treated samples all showed a higher microhardness than the raw Ti-6Al-4V, and the L-13.5W sample had the highest value among all 3 samples. This is supposedly due to a higher amount of dissolved oxygen with the formation of oxides throughout the high temperature laser process, the refinement of the microstructure and the formation of martensite during rapid quenching [20]. Higher surface microhardness is expected to be helpful for the wear resistance properties of Ti-6Al-4V biomedical implant applications.

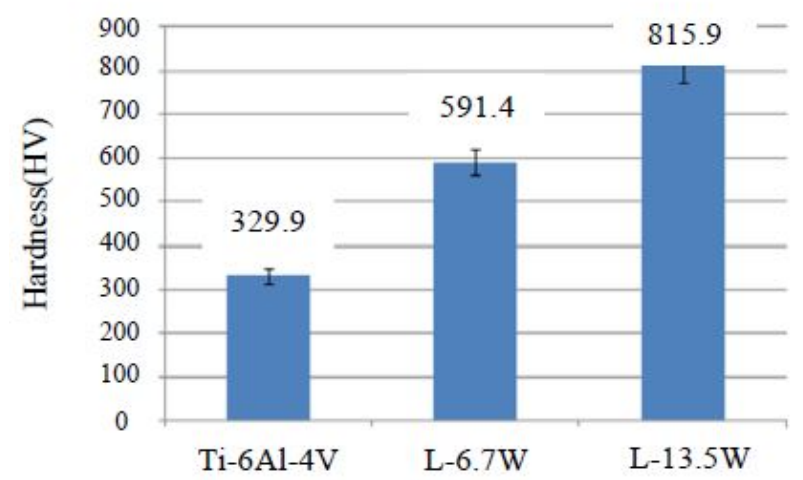

Fig. 3 Microhardness of raw and laser-treated Ti-6Al-4V samples

\subsection{Wettability}

Figure 4 shows the schematic of contact angle and the wettability results of the raw and laser treated Ti-6Al-4V samples. The wettability test was carried out with the $\mathrm{m}-\mathrm{SBF}$ control liquid. It is shown that the hydrophilicity of the raw Ti-6Al-4V was dramatically improved after the laser irradiation process, and the L-13.5W sample had the best hydrophilicity performance. Lawrence et al. [14] indicated that the improvements in the wettability characteristics of their fiber laser treated Ti-6Al-4V alloy were found to be due to: (i) an increase in the surface roughness; (ii) an increase in the surface oxygen content and (iii) an increase in the polar component of the surface energy, which had the same findings with our study here.

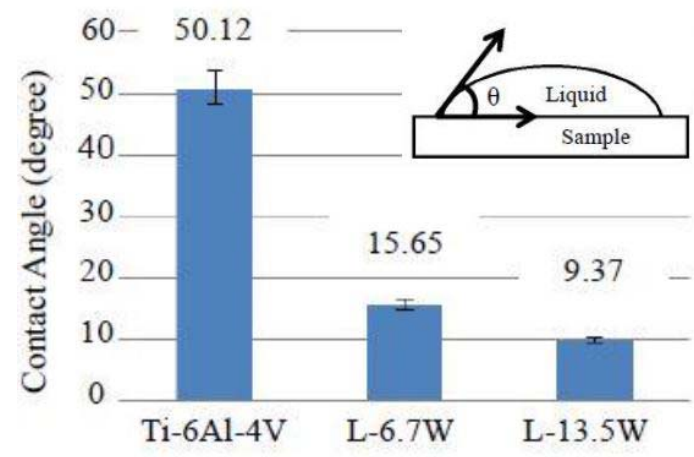

Fig. 4 The wettability of raw and laser-treated Ti-6Al-4V samples

\section{$3.5 \mathrm{~m}-\mathrm{SBF}$ in vitro bioactivity evaluation}

Figure 5 reveals the SEM surface morphology Ti-6Al-4V samples after immersion in $\mathrm{m}-\mathrm{SBF}$ for several different periods of time. It can be observed from Fig. 5 that increasing accumulations were found on the coral-like structures of those laser-treated Ti-6Al-4V samples with the increase in immersion time in $\mathrm{m}-\mathrm{SBF}$, whereas the raw Ti-6Al-4V samples did not show much difference. After 21 days of immersion in $\mathrm{m}-\mathrm{SBF}$, a thin layer of accumulation can be seen on the surfaces of the two laser-treated samples. Figure 6 compares the SEM image of the L-13.5W sample after immersion in m-SBF for 14 and 21 days, respectively, and also reveals their EDS chemical compositions. It can be seen that the accumulations (\#2) are $\mathrm{Ca} / \mathrm{P}$-rich agglomerates, and the 21-day sample has a relatively larger $\mathrm{Ca}$ and $\mathrm{P}$ content than that of its 14-day counterpart.

Observing these laser-treated samples, it is obvious that the $\mathrm{Ca}$ and $\mathrm{P}$ increased with the increase in immersion time, whereas the raw Ti-6Al-4V samples did not show much difference and there is no evidence that $\mathrm{Ca}$ and $\mathrm{P}$ were detected even after 21 days of immersion (Fig. 7). The XRD measurements, shown in Fig. 8, reveal that crystalline hydroxyapatite (HA) was found on the laser-treated samples after a 21-day immersion, and the L-13.5W sample had a stronger HA spectra than its L-6.7W counterpart.

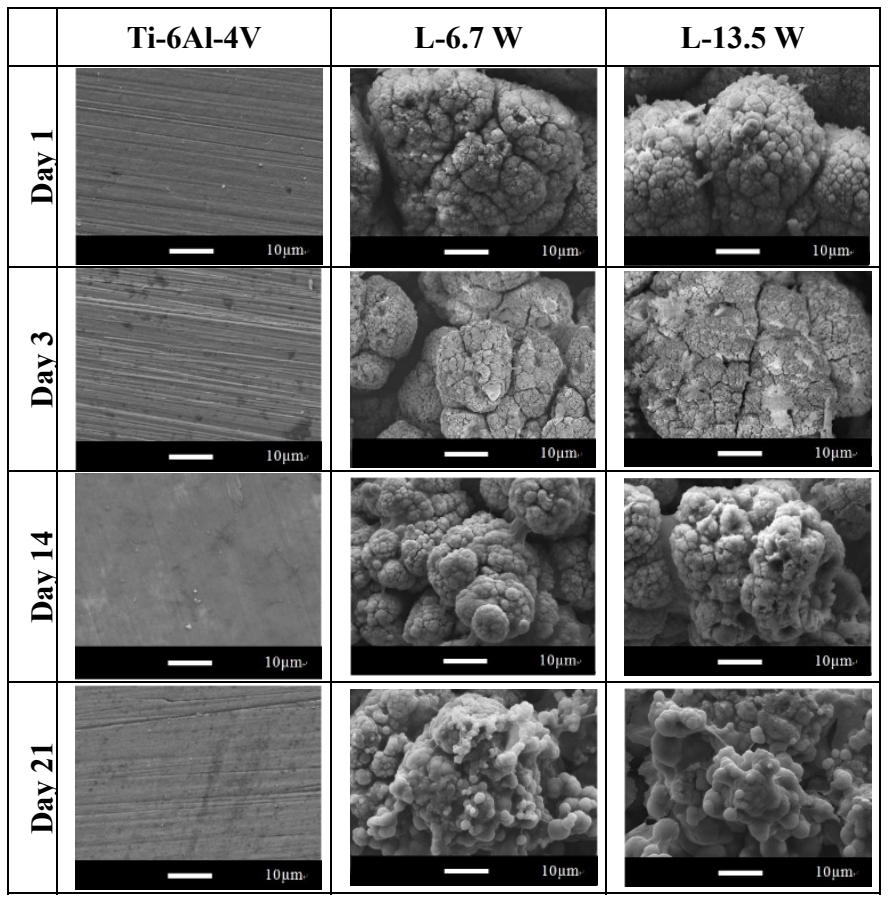

Fig. 5 The SEM image of specimen surfaces after immersion in $\mathrm{m}-\mathrm{SBF}$ for different periods of time 


\begin{tabular}{|c|c|c|c|c|}
\hline \multirow{2}{*}{\multicolumn{2}{|c|}{ SEM }} & \multicolumn{3}{|c|}{ EDS(At\%) } \\
\hline & & & $\# 1$ & $\# 2$ \\
\hline \multirow{6}{*}{$\frac{\Delta}{\vec{D}}$} & & $\mathrm{Ti}$ & 41.86 & 0.37 \\
\hline & & $\mathrm{Al}$ & 4.22 & 0.21 \\
\hline & & $\mathrm{V}$ & 1.51 & 0.01 \\
\hline & & $\mathrm{O}$ & 47.27 & 79.60 \\
\hline & & $\mathrm{Ca}$ & 2.79 & 11.23 \\
\hline & & $\mathrm{P}$ & 2.35 & 8.58 \\
\hline \multirow{6}{*}{$\begin{array}{l}\vec{N} \\
\vec{\Xi} \\
\vec{D}\end{array}$} & & $\mathrm{Ti}$ & 39.03 & 0.33 \\
\hline & & $\mathrm{Al}$ & 1.49 & 0.12 \\
\hline & & $\mathrm{V}$ & 1.68 & 0.10 \\
\hline & & $\mathrm{O}$ & 45.11 & 59.11 \\
\hline & & $\mathrm{Ca}$ & 8.66 & 26.32 \\
\hline & & $\mathrm{P}$ & 4.03 & 14.03 \\
\hline
\end{tabular}

Fig. 6 SEM image and EDS chemical composition of L-13.5W surfaces after immersion in $\mathrm{m}-\mathrm{SBF}$ for 14 days and 21 days

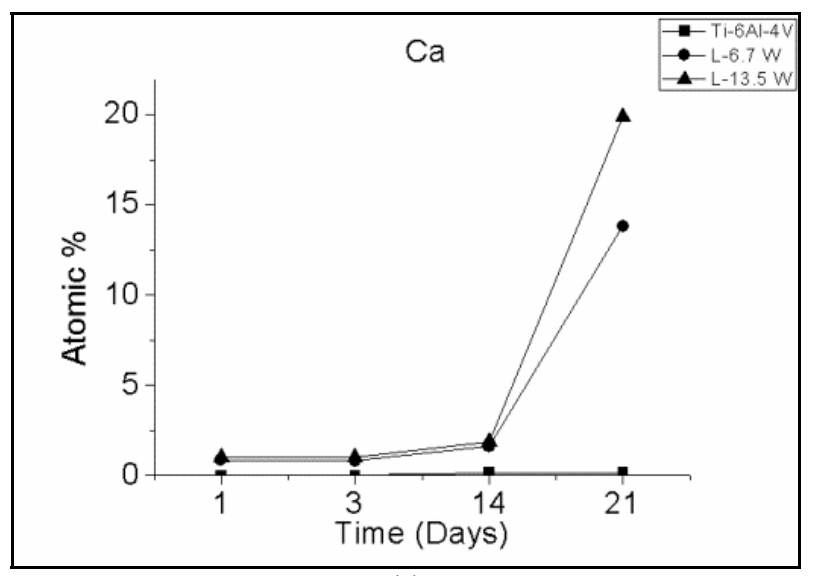

(a)

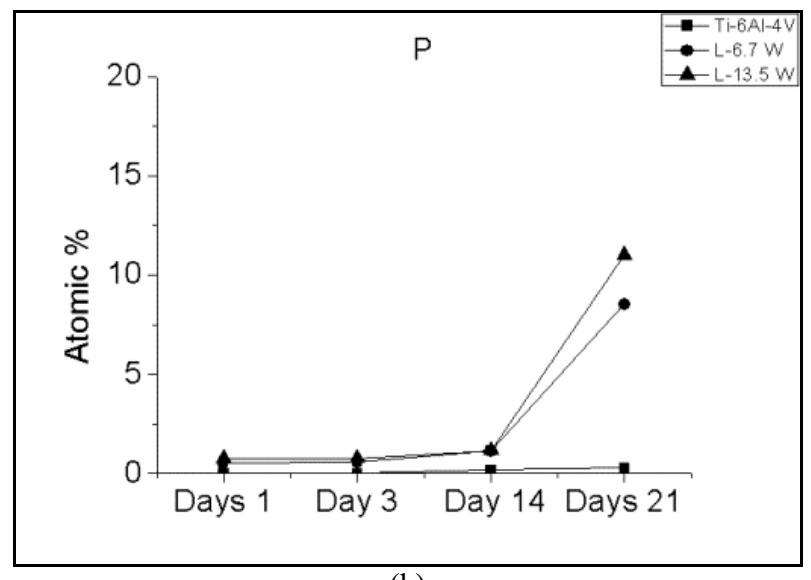

(b)

Fig. 7 The EDS chemical composition of specimen surfaces after immersing in $\mathrm{m}-\mathrm{SBF}$ for different periods of time: (a) $\mathrm{Ca}$ and (b) $\mathrm{P}$

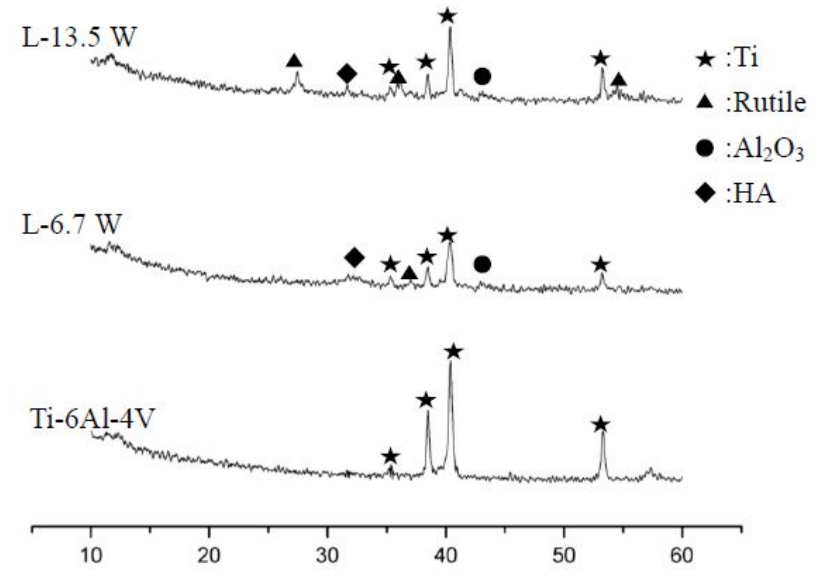

Fig. 8 The crystal phases of specimens' surfaces after immersion in $\mathrm{m}$-SBF for 21 days

The above results indicate that the accumulations observed in Fig. 5 were $\mathrm{Ca} / \mathrm{P}$-rich agglomerates, and the laser-treated samples had a better $\mathrm{Ca}$ and $\mathrm{P}$ inducibility than raw Ti-6Al-4V in the m-SBF due to rougher surfaces and better hydrophilicity than raw samples [21]. Since the ion concentration of $\mathrm{m}-\mathrm{SBF}$ was similar to that of human body fluid, it provided a biomimetic environment for the samples, and hence the HA-enriched bone-like apatite was observed from those laser-treated samples after 21 days of $\mathrm{m}-\mathrm{SBF}$ immersion. The results also reveal that the L-13.5W sample had the best in vitro bioactivity among three samples, which outstanding performance is favorable for biomedical implant applications.

\section{6 $1.5 \mathrm{~m}$-SBF biomimetic coating}

After immersion the samples in supersaturated 1.5 $\mathrm{m}$-SBF for different periods of time, it can be observed from Fig. 9 that increasing accumulations were found not only on the coral-like structures of those laser-treated Ti-6Al-4V samples but also on the raw Ti-6Al-4V counterpart with the increase in immersion time in 1.5 $\mathrm{m}-\mathrm{SBF}$. A thin layer of accumulation can be seen on the surfaces of the two laser-treated samples after 3 day immersion in $1.5 \mathrm{~m}-\mathrm{SBF}$.

In addition, it is obvious that the $\mathrm{Ca}$ and $\mathrm{P}$ of all samples increased with immersion time, where the L-13.5W sample has the highest overall $\mathrm{Ca}$ and $\mathrm{P}$ content (Fig. 10). A rich $\mathrm{Ca}$ and $\mathrm{P}$ spectra became apparent after samples were immersed in $1.5 \mathrm{~m}$-SBF for only 3 days, but could only be observed from L-13.5W samples when immersed in m-SBF for 21 days. The XRD measurements, shown in Fig. 11, also reveal that crystalline HA was found from the laser-treated samples after only 3 days of immersion in $1.5 \mathrm{~m}-\mathrm{SBF}$. Moreover, the L-13.5W sample had the weakest Ti spectra and also the richest $\mathrm{Ca}$ and $\mathrm{P}$ content, which indicates that it had the richest HA-enriched bone-like apatite among all three samples.

The above results indicate that when samples were immersed in the supersaturated $1.5 \mathrm{~m}-\mathrm{SBF}$, which had a 1.5 times higher ion concentration than m-SBF, HA-enriched bone-like apatite could be effectively formed on their 
surfaces via this biomimetic process. The L-13.5W sample still showed the most outstanding coating efficiency among all specimens, which suggests a potential bioactive layer coating method on Ti-6Al-4V surfaces for improving its biocompatibility.

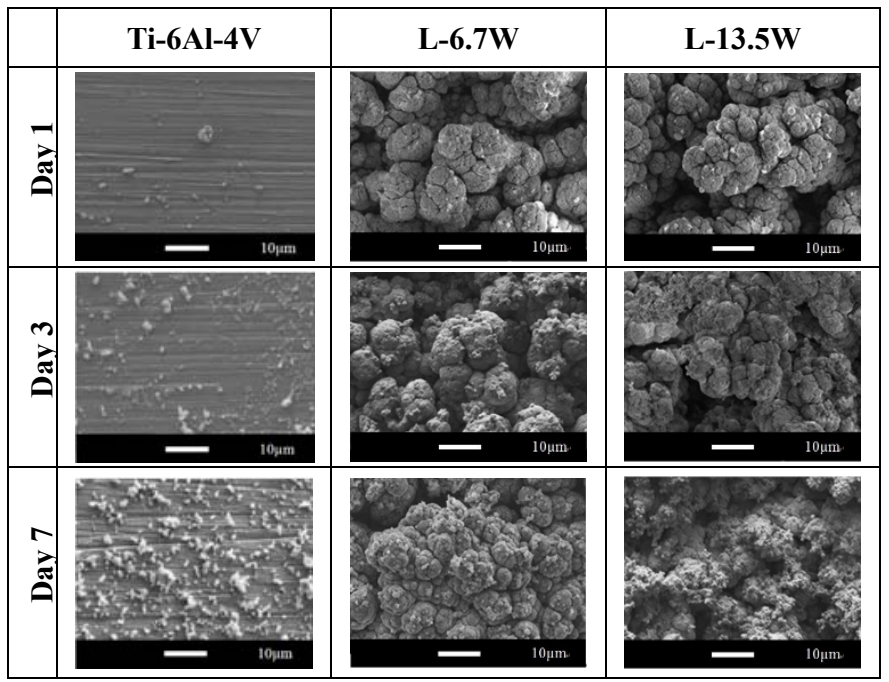

Fig. 9 SEM images of specimens' surfaces after immersion in 1.5 $\mathrm{m}$-SBF for different periods of time
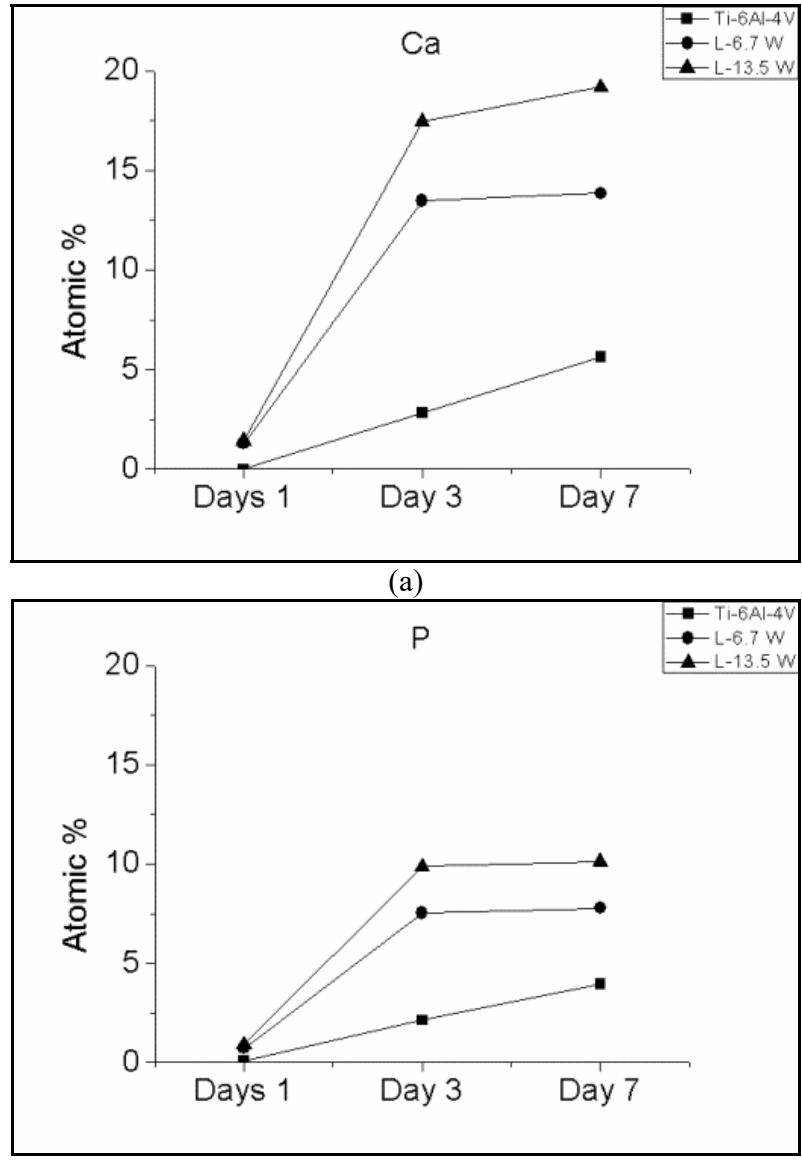

(b)

Fig. 10 The EDS chemical composition of specimens' surfaces after immersion in $1.5 \mathrm{~m}-\mathrm{SBF}$ for different periods of time: (a) $\mathrm{Ca}$ and (b) P

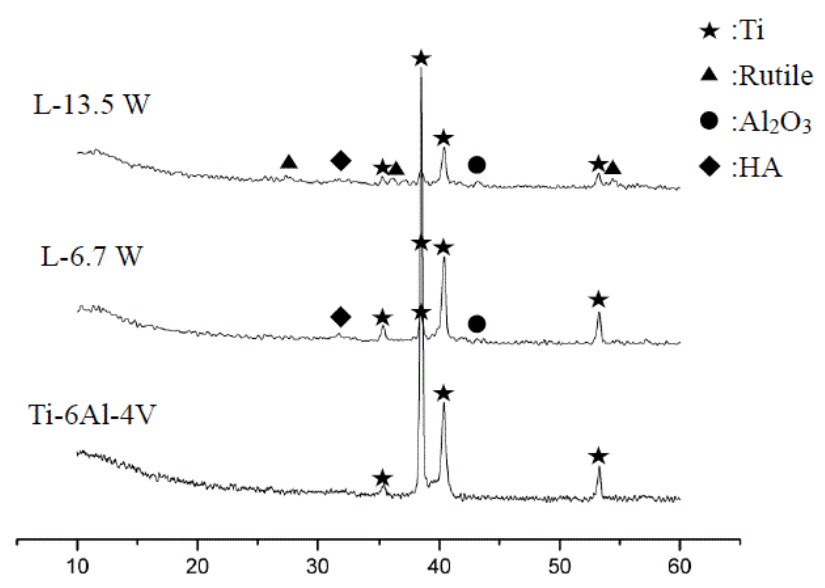

Fig. 11 The crystal phases of specimens' surfaces after immersion in $1.5 \mathrm{~m}$-SBF for 3 days

\section{Conclusion}

The results show that rough oxidized surfaces were created on Ti-6Al-4V, and their hardness and hydrophilicity were also improved after fiber laser treatment. The $13.5 \mathrm{~W}$-treated sample had a relatively higher hardness and more outstanding hydrophilicity compared with its 6.7W-treated counterpart. Furthermore, the laser treated samples were found to have a more favorable $\mathrm{Ca}$ and $\mathrm{P}$ inducibility in the m-SBF than raw Ti-6Al-4V. A layer of bone-like apatite can be rapidly formed on the specimens when immersed in a $1.5 \mathrm{~m}-\mathrm{SBF}$ solution for only 3 days, indicating its favorable biomimetic coating efficiency.

\section{Acknowledgments}

The authors would like to thank the Ministry of Science and Technology, Taiwan, for financially supporting this research under Contract No. MOST 103-2221-E-020 $-022$

\section{References}

[1] P. Cheang and K. A. Khor: Biomaterials, 17, (1996) 537.

[2] C. M. Lopatin, V. Pizziconi, T. L. Alford and T. Laursen: Thin Solid Films, 326, (1998) 227.

[3] J. Lenka, A. Frank, H. Aleš, S. Jakub and G. Peter: Biomaterials, 25, (2004) 1187.

[4] C. F. Lu, H. M. Huang, C. H. Chu, W. L. Li and T. F. Hong: Procedia Eng., 36, (2012) 179.

[5] J. Kaspar, J. Bretschneider, S. Jacob, S. Bonß, B. Winderlich and B. Brenner: Surface Eng., 23, (2007) 99.

[6] Y. S. Tian, C. Z. Chen, S. T. Li and Q. H. Huo: Appl. Surf. Sci., 242, (2005) 177.

[7] Y. Wang, C.G. Li, L.X. Guo and W. Tian: Surf. Coat. Technol., 204,(2010) 3559.

[8] Y. Wu, A.H. Wang, Z. Zhang, R.R. Zheng, H.B. Xia and Y.N. Wang: Appl. Surf. Sci., 305, (2014) 16.

[9] Y. Chen, D.J. Wu, G.Y. Ma, W.F. Lu and D.M. Guo: Surf. Coat. Technol., 228, (2013) S452.

[10] G. P. Dinda, J. Shin and J. Mazumder: Acta Biomater., 5, (2009) 1821.

[11] C. S. Chien, T. F. Hong, T. J. Han, T. Y. Kuo and T. Y. Liao: Appl. Surf. Sci., 257, (2011) 2387. 
[12] C. S. Chien, T. Y. Liao, T. F. Hong, T. Y. Kuo, C. H. Chang, M. L. Yeh and T. M. Lee: J. Med. Biol. Eng., 34, (2014) 109.

[13] N. Moritz, S. Areva, J. Wolke and T. Peltola: Biomaterials, 26, (2005) 4460.

[14] J. Lawrence, L. Hao and H. R. Chew: Surf. Coat. Tech., 200, (2006) 5581.

[15] N. Zaveri, M. Mahapatra, A. Deceuster, Y. Peng, L. Li and A. Zhou: Electrochim. Acta, 53, (2008) 5022.

[16] M. Roy, B. Vamsi Krishna, A. Bandyopadhyay and S. Bose, Acta biomater., 4, (2008) 324.

[17] T. F. Hong, K. P. Chi, H. K. Lin and Y. D. Wu: J. Laser Micro Nanoen., 9, (2014) 64.

[18] T. Kokubo and H. Takadama: Biomaterials, 27, (2006) 2907

[19] A. Oyane, H. M. Kim, T. Furuya, T. Kokubo, T. Miyazaki and T Nakamura: J. Biomed. Mater. Res., 65A, (2003) 188.

[20] E. Chikarakara, S. Naher and D. Brabazon: Surf. Coat. Tech., 206, (2012) 3223.

[21] M. Bohner and J. Lemaitre: Biomaterials, 30, (2009) 2175

(Received: May 25, 2015, Accepted: March 2, 2016) 